http://dx.doi.org/10.12775/szhf.2015.006

\title{
Od kiedy krytykujemy Kanta? Wersja litewska
}

W literaturze przedmiotu za początek recepcji filozofii Immanuela Kanta na terenach Rzeczypospolitej Obojga Narodów przyjmuje się koniec XVIII oraz przełom XVIIII XIX wieku. W tym kontekście wskazuje się przede wszystkim na polskie tłumaczenia Zum ewigen Frieden ${ }^{1}$ oraz na inne, mniejszej skali, polskie reakcje na teksty Kanta. Litewscy badacze, roztrząsający dzieje filozofii na Litwie, przez długi czas korzystali z polskich badań, uzupełniając je o informacje na temat krytyki antropologii Kanta (w r. 1786) pióra wileńskiego profesora Johanna Georga Adama Forstera, czy też na temat Johanna Heinricha Abichta, niezbyt wiernego, choć zdeklarowanego stronnika Kanta, profesora wydziału Filozofii Teoretycznej i Praktycznej w Cesarskim Uniwersytecie Wileńskim.

Podręcznik filozoficznej myśli litewskiej ${ }^{2} \mathrm{z}$ czasów sowieckich skrywa ledwie dostrzegalną osobliwość: na stronie poświęconej twórczości Kazimierza Narbutta ${ }^{3}$, na liście autorytetów, z których ów myśliciel korzystał (lub które krytykował), widnieje nazwisko I. Kanta (obok Arystarcha, św. Augustyna, Arystypa z Cyreny, Chryzypa, Cycerona, Demokryta, Corsiniego, Epikteta,

\footnotetext{
${ }^{1}$ Projekt wieczystego pokoju; rozwaga filozoficzna przez E. Kanta z języka francuskiego z nowymi autora doatkami, tłum. Szymon Bielski, Königsberg 1796, Warszawa 1797.

${ }^{2}$ Lietuvos filosofinès minties istorijos šaltiniai, t. 1, Vilnius 1980, s. 219.

${ }^{3}$ Jego autorem jest m.in. Aloyzas Varanavičius (wspomniany podręcznik jest de facto dziełem zbiorowym). A. Varanvičius dysponował możliwością prac badawczych w archiwach Kijowa, tam opisał rękopis K. Narbutta, o którym będzie jeszcze mowa.
} 
Euklidesa, Gassendiego, Genueńczyka, Hobbesa, Campanelliego, Keplera, Kopernika, Leibniza, Locke’a, Malebranche'a, Spinozy i tuzina innych). Wzmianka ta była na pozór niewiele znacząca - wiadomo, że eklektycy (do tego prądu filozoficznego należał Narbutt) korzystali z intelektualnych osiągnięć różnej proweniencji. Jednakowoż wzmianka ta mogła w późniejszym czasie zostać bezkrytycznie wykorzystana w historycznych badaniach litewskich $^{4}$ nad recepcją Kanta (analogiczne, często mylące zdarzenia, co trzeba odnotować, nie należą do rzadkości w podręcznikach i encyklopediach polskich).

W roku 2008 owa „Kantowska wzmianka” wzbudziła pewne podejrzenia u piszącego te słowa. Zgodnie z nią bowiem Narbutt o Mędrcu Królewieckim dowiedział się niewiarygodnie wcześnie, tj. w roku 1764, a wiadomo skądinąd, że „Kantowska rewolucja w sposobie myślenia” datuje się od 1781 roku, czyli od publikacji „Krytyki”. Jest to o tyle zastanawiające, że takie kraje, jak Francja, Wielka Brytania, Włochy, Holandia, cała Skandynawia, Bałkany (oprócz Prus oraz innych państw niemieckojęzycznych) zapoznały się z filozoficzną myślą Kanta relatywnie późno, tj. pod sam koniec XVIII w., a w zasadzie w pierwszej dekadzie XIX w. Sami badacze niemieccy, posługujący się pojęciem „Die erste Kant Rezeption”, datują recepcję Kanta w Niemczech od 1786 roku - od tekstów Reinholda, Maimona, Schellinga oraz Fichtego ${ }^{5}$.

Sprawdzenie trafności informacji o niezwykle wczesnej recepcji Kanta stało się jednym z zadań misji badawczej w archiwach ukraińskich, w której wzięli udział autor tego artykułu oraz znawca historii filozofii XVIII w., Steponas Tunaitis (1940-2011). Właśnie w Kijowie, w Bibliotece Akademickiej im. Vernadskiego przechowywany jest jedyny rękopiśmienny egzemplarz wykładów Kazimierza Narbutta pod tytułem Institutiones Philosophiae ecklecticae [...] a patrae Casimiro Narbuti. Dombrovicae, anno 1764 in $1765^{6}$. Sumienność i kompetencje naukowe jego odkrywcy - Aloyzasa Waranavičiusa - nie wzbudzały żadnych wątpliwości; chodziło w pierwszym rzędzie o ustalenie całego kontekstu wiedzy na temat Kanta. Owo niełatwe skądinąd zadanie (całość wykładów to 668 stron niejasnego, pospiesznie zapisanego i kiepskiej

${ }^{4}$ St. Tunaitis, Kantizmo sklaida, [w:] Apšvietos ir romantizmo kryžkelèse. Filosofijos kryptys ir kontroversijos XVIII a. pabaigoje - pirmoje XIX a. puséje, Vilnius 2008, s. 35.

${ }^{5}$ Ilustracją może tu być, przykładowo, nazwanie międzynarodowego seminarium naukowego pod tytułem Kant und die erste Kant-Rezeption (1786-1796), które dziesięć lat temu odbyło się w Uniwersytecie Eberharda Karola w Tybindze: http://tiss.zdv.uni-tuebingen.de/webroot/ fp/fpsfr01_SoSe_2004.

${ }^{6}$ NBUV (Nacionalnaja biblioteka Ukrainy im. V. I. Vernadskovo), IR, f. 1., d. 4456, s. 130. 
jakości tekstu) zostało zręcznie wykonane. Na stronie 130 odcyfrowano wyrażenie „Cantzius” w kontekście krytyki nieadekwatnego, zdaniem Narbutta, pojęcia substancji. Odkrycie okazało się jednak przedwczesne. Pojawił się bowiem inny kandydat na właściciela tego nazwiska, a mianowicie teolog ewangelicki z Wirtembergii, Gottlob Israel Kanc (1690-1753). Wyraz fonetyczny tego nazwiska jest w języku łacińskim całkowicie identyczny ze zlatynizowanym nazwiskiem Kanta - „Kantius”. Krótko mówiąc, oba nazwiska brzmią jednakowo. Zostało ponadto ustalone, że zapis wykładów Narbutta został sporządzony „ze słuchu“ przez nieznanego studenta Kolegium Dąbrowickiego ${ }^{7}$. Ponadto wyłącznie jeden $\mathrm{z}$ wariantów nazwiska teologa Canza obok wersji „Canz”, „Canzio”, „Canzius”, „Canzen” - występuje z literami „tz”, tj. "Cantzius” (Katalog der Thüringer Universitäts und Landsbibliothek Jena [http://kataloge.thulb.uni-jena.de/]). W tym świetle nasze zagadnienie przybiera kształt prostego pytania: kto pierwszy pojawił się w Rzeczpospolitej Obojga Narodów - Kant czy Kanc?

Dalsze, skrótowe przedstawienie argumentacji pro et contra wymaga znajomości oryginału. Dyskusja dotycząca fragmentów wykładów (rekonstrukcja rękopiśmiennego oryginału i przekład polski) Narbutta jest zamieszczony w zakończeniu tego artykułu.

Taktyka badań oraz wnioski historyków litewskich w tej kwestii były zróżnicowane. Krótki spór odbył się w kulturalno-filozoficznym periodyku litewskim „Logos” (2009, nr 50 i 2010, nr 62). Stepas Tunaitis, stronnik „wersji Kanca", dostrzegł w tym wypadku skromny wkład w badania recepcji szkoły Chrystiana Wolffa (dalej - wolfianizmu) na Litwie i w Polsce: „Odkrycie, że Litwa przez orientację Canza dążyła za teologicznym wolfianizmem jako jedną z dość peryferyjnych gałęzi, wyrastających ze szkoły Wolffa, nieco rozszerza nasze rozumienie ideowych związków i źródeł początkowego etapu Oświecenia. Takie odkrycie wzbogaca wolfianizm litewski, który, zapoczątkowany w połowie XVIII w., dosyć szeroko rozwinął się przez dwa dziesięciolecia"s.

Moim zdaniem, łacińskojęzyczny charakter nauki i filozofii w Rzeczypospolitej dał asumpt do być może jednorazowej recepcji, w tym wypadku recepcji negatywnej („odrzucającej”) poglądów przedkrytycznego Kanta, który

${ }^{7}$ R. Plečkaitis, Kazimieras Narbutas ir šviečiamoji filosofija Lietuvoje, Kazimieras Narbutas, Raštai, Vilnius, 1989, s. 12.

${ }^{8}$ S. Tunaitis, Sueitis su ikikritine I. Kanto filosofija Apšvietos Lietuvoje. Versijos ir kontroversijos, „Logos“, nr 60, Vilnius 2009, s. 46. 
publikował niektóre wczesne dzieła po łacinie. To skromny wkład w badania spuścizny filozofii eklektyzmu. Jednakże, jako weryfikowalny, wniosek taki stanowi niejaki wkład również w kantyzm polski, litewski, a także białoruski (zważywszy na pochodzenie Narbutta) oraz ukraiński (Kolegium Dąmbowickie funkcjonowało na terenie obecnej Ukrainy): wskazuje on na prapoczątek recepcji Kanta w czterech krajach (złączonych w jeden organizm państwowy).

Główny argument, że imię własne „Cantzius” wskazuje bawarskiego teologa Kanza, jest następujący. Wysiłek Narbutta jest skierowany ku obronie jednej ze zdobyczy początkowego Oświecenia - ustanowienia jasnej i nieprzekraczalnej granicy między filozofią i teologią, która swe prawdy uzasadnia Pismem Świętym oraz tradycją. Natomiast teolog Kanc był inicjatorem prądu wolfianizmu teologicznego (Theologische Wolffianismus). Próbował on - racjonalnymi (a w szczególności - wolfiańskimi) środkami rekonstruować prawdy teologiczne, Pismo Święte wyjaśniać w duchu znanych zasad Leibniza-Wolffa. Zatem wąska granica między teologią i nową, tj. „rzeczywistą" (według Narbutta) filozofią zostałaby ponownie zatarta. Stąd też bierze się wniosek (który, nawiasem mówiąc, w czasach sowieckich stanowiłby pożądane odkrycie dla tzw. „historyków ateizmu naukowego”), że interpretacja pojęcia substancji opierająca się na pojęciu „celów Boga” (zgodnie z wykładnią „Kantziusa”, tj. Kanca) jest niepoprawna. Jako dowód za „Kancem” Steponas Tunaitis przytacza cytat słynnego podręcznika logiki Narbutta (1769) w której mówi się o przemądrzałych dzisiejszego wieku, którzy teologię, czyli naukę o Bogu i jego przymiotach, przedstawiają jako umiejętność rozumu.

Rozstrzygnięcie takie byłoby trafne, gdyby przytaczany (niżej) fragment był z zakresu teologii naturalnej. Tak jednak nie jest: jest to ustęp z ontologii. W swej Logice ${ }^{10}$ Narbutt nie tyle atakuje teologię naturalną (ona była pełnowartościowym przedmiotem filozoficznym), ile broni teologii objawionej, która jest rozumem ludzkim nieujmowalna. W wykładach z lat 1764-1765, $\mathrm{w}$ interesującym nas dziale ontologii, wyraźnie twierdzi, że Cantzius jest „metafizykiem” (więc nie teologiem, jak Kanz, który był szeroko znany właśnie jako „teolog”). Przekonanie, że „farvater”, czy „locus communis” filozofii Oświecenia w Polsce i Litwie był wprost neurotyczny strach przed powrotem

\footnotetext{
${ }^{9}$ S. Tunaitis, Sueitis su ikikritine I. Kanto filosofija Apšvietos Lietuvoje. Versijos ir kontroversijos, „Logos” nr 60, Vilnius 2009, s. 46.

${ }^{10}$ Logika, czyli rozważania i rozsądzania rzeczy nauka, według której każdy ma we wszystkim prawdy dochodzić i strzec się fatszu, Wilno 1769.
} 
„mgieł barbarzyńskiej scholastyki”, stanowi powszechną wiedzę. Jednak Narbuttowi w tym wypadku chodziło o coś zupełnie innego: nie o zwalczanie recydywy scholastyki, nie o obronę granic teologii objawionej, lecz jedynie o prawidłowe pojęcie substancji.

Odnotowaliśmy już, że Narbutt był eklektykiem (sam nie szczędzi pochwał temu prądowi intelektualnemu, nota bene podobnie, jak Denis Didederot w Encyklopedii). Osiemnastowieczny eklektyzm w Polsce swe pryncypia „wolnego wyboru” szeroko stosował w dziedzinie spsychologizowanej logiki, ale w kwestiach ontologii dosyć wiernie, co trzeba podkreślić, trzymał się poglądów szkoły Leibniza-Wolffa ${ }^{11}$. Pozostaje ustalonym faktem okoliczność, niejednokrotnie potwierdzana przez kompetentnych badaczy polskich i litewskich (Olgierd Narbutt, 1958, Romanas Plečkaitis, 1989), że zarówno twierdzenia i podstawowe definicje metafizyczne, ontologiczne, jak też i cała struktura filozofii K. Narbutta jest odziedziczona po szkole Wolffa. Biorąc za osnowę niniejszą konstatację, możemy sformułować następującą argumentację na rzecz „kandydatury Kanta”:

- Narbutt przedstawia wolffianisticzne pojęcie substancji (substancja siła działająca) jako poprawne.

- Narbutt odrzuca pojęcia substancji, które jawnie nie zgadzają się z odnośnym pojęciem u Woffa.

- Teolog Kantz był wolfianistą. Jego pojęcie substancji jest identyczne z pojęciem u Wolffa i Narbutta (np. dzieło Kanca Philosophia fundamentalis, paragraf 696: „Ergo vis agendi est substantia”).

- Narbutt odrzuca pojęcie substancji teologa Kanca lub filozofa Kanta; jeżeli tertium non datur, to odrzuca on pojęcie substancji nie Kanca, lecz Kanta.

Poprzednik implikacji we wniosku - tertium non datur - jest najsłabszym ogniwem niniejszego sylogizmu. Być może owo „tertium” jest zwykłą pomyłką w "filozoficznym dyktandzie" spisującego wykłady młodego słuchacza, a być może - błędem samego wykładowcy. Jednak sytuacja nie jest beznadziejna - możliwe są dodatkowe argumenty, że niezbyt przejrzyste twierdzenia tajemniczego „Kantziusza”, przekazane ustami Narbutta, rzeczywiście mają odpowiedniki w filozofii wczesnego Kanta. Co przemawia za filozofem Kantem, w Królewcu w tym czasie cieszącym się już z niejakiej sławy?

${ }^{11}$ Np. O. Narbutt, O pierwszym polskim podręczniku logiki. Z rozważań nad filozofią Oświecenia, Łódz1958; Nowożytna myśl naukowa w szkołach i kięgozbiorach polskiego Oświecenia, red. I. Stasiewicz-Jasiukowa, Wrocław-Warszawa-Kraków-Gdańsk 1976. 
Szkoła wolfianistow była stosunkowo jednolita, spory w gronie zwolenników Wolffa należały do rzadkości. W wykładach kolegialnych dominowały definicje filozofii o charakterze podręcznikowym, definicje jednoznaczne; aby podkreślić cechy „prawdziwego” określenia, przytaczano wywody przedstawicieli nie ze „swojej”, lecz „obcej”, wrogiej szkoły, bardzo często - autorów zamieszczonych w indeksie Librum prohibitum. Jak ustaliła Irena Stasiewicz Jasiukowa, papież rzymski Klemens XIII wydał oficjalne pozwolenie Narbuttowi na korzystanie z Indexu (Narbutt został obdarzony tzw. indultem). Jak pisze K. Vorländer, dzieło Kanta Der einzig mögliche Beweisgrund zu einer Demonstration des Daseins Gottes zostało włączone do Indexu. Kiedy do tego doszło? Właściwie na krótko przed tym, gdy Narbutt rozpoczął swoją działalność pedagogiczną, a dokładniej - przed spisaniem jego wykładów. Zatem Kant znalazł się w obozie „wrogich”. Przeciwny stosunek do szkoły Wolffa reprezentował Chrystian August Crusius. W tym czasie, gdy Narbutt przygotowywał swoje wykłady, Kant wraz z Crusiusem byli już oponentami wolfianizmu. Kant w swojej łacińskiej rozprawie habilitacyjnej pod skróconą nazwą Nova dilucidatio... aż pięć razy chwali Crusiusa jako genialnego oponenta Wolffa, a tego ostatniego wymienia jedynie trzy razy i to tylko w pejoratywnym kontekście. Należy zatem skierować swą uwagę na dzieło Kanta Principiorum primorum cognitionis metaphysicae nova dilucidatio (Nowe oświetlienie pierwszyczh principuf metafizycznego poznania), $1755 \mathrm{r}$. Warto przy tym zauważyć, że dla Narbutta stanowisko tajemniczego Cantziusza również stanowi novum, gdy oświadcza „spieszę śmiało odrzucić”; z pewnością nie ma on na myśli Spinozy, którego wszyscy już dobrze znali i dość powszechnie w Rzeczypospolitej odrzucali, lecz kogoś zupełnie innego.

Hipotetycznie zatem ów nowy zwrot wykonał Kantzius wraz ze swoimi towarzyszami metafizykami (prawdopodobnie - z Crusiusem). Kantcius, jak uczniom mawiał Narbutt, mylnie twierdzi, jakoby cechy substancji (specimina, czyli akcydensy) powstawały nie z jej siły aktywnej, lecz były jej przez kogoś nadawane - mianowicie przez Boga. Takie sformułowania możemy odnaleźć w Powszechnej historii naturalnej i teorii nieba. Kant twierdził w niej, że celem ogółu stworzonego wszechświata jest ucieleśnienie zamysłu Boga. Natomiast w rozprawie habilitacyjnej Nova dilucidacio możemy znaleźć dwie kolejne istotne nowości, a mianowicie metafizyczne zasady: principium succesionis (następstwa) oraz principium coexistenciae (współistnienia). Wykazując działanie tych zasad, Kant argumentuje, że związek substancji ma swój zamysł w czynnej reprezentacji boskiego intelektu, a reprezentacja ta zależy całkowicie od Boga. Twierdzi on dalej, że system obustronnych związków 
substancji, mający podstawę w Bogu, jest doskonalszy od wolfiańskiego systemu fizycznego oddziaływania. Nowy system pozwala odkryć, w jaki sposób powstają wspomniane związki następstwa i współistnienia. Nie należy się ich doszukiwać w jakiejś immanentnej zasadzie substancji. Substancje oddziałują nie dzięki „sile wewnętrznej działającej”. Związek zewnętrzny jest niemożliwy bez stosunków wzajemnych. Stosunki wzajemne implikują jedyną przyczynę. Jedyna przyczyna świadczy o zamyśle Boga (słowami Narbutta: "o celach Boga"). W ten sposób uzyskujemy wszystkie elementy, którymi Narbutt charakteryzuje stanowisko „Cantziusza” - cechy substancji powstają nie z samej substancji, lecz pochodzą bezpośrednio od Boga (świat posiada takie, a nie inne cechy, by realizować cel Boga). Roztrząsania niniejsze, które Narbutt przyjmował bez szerszego kontekstu koncepcji przedkrytycznego Kanta, wydają się dość trywialne i mają teologiczny charakter. Kontekst ten Narbutt brał w nawias; interesował go jedynie określony aspekt koncepcji młodego Kanta: konieczny związek pojęcia istnienia substancji z pojęciem Boga. On sam związek tego typu zdecydowanie odrzucał.

Dlaczego myśliciele litewscy i polscy najpierw zapomnieli o Kancie, a potem ponownie odkryli go pod koniec XVIII wieku? Odpowiedź na to pytanie może być zaskakująco prosta: dlatego, że Kant przestał pisać po łacinie. Polsko-litewska filozofia uprawiana była bowiem początkowo główne w języku łacińskim, a następnie - $\mathrm{w}$ języku francuskim. Znajomość zaś języka niemieckiego była kiepska, a większość filozofów w ogóle nie korzystała z niemieckich oryginałów, co zresztą potwierdza późniejsza głośna krytyka Kanta autorstwa Jana Śniadeckiego, rektora Uniwersytetu Wileńskiego.

Podsumowując, skłaniałbym się ku twierdzeniu, że laur pierwszeństwa w światowym antykantyzmie należy do Litwina, Kazimierza Narbutta. Wydaje się, iż kolejny ruch badawczy należy teraz do polskich kolegów, w tym - do ewentualnych polemistów. Chciałbym wyrazić przy okazji serdeczne podziękowania Mariuszowi Grygiańcowi, filozofowi warszawskiemu, który pomógł nadać tekstowi bardziej polskie brzmienie, oraz Tomaszowi Kupsiowi, toruńskiemu koledze, który nieustannie zachęca do poszukiwań śladów myśli Kanta w intelektualnym dziedzictwie naszych krajów. 
Narbutt Kasimirus

\section{Institutiones Philosophiae Eclecticae. Anno 1764 in 1765 (NBUV [Biblioteka Narodowa Ukrainy im. V. I. Vernadskovo], IR, f. 1., d. 4456, p. 130)}

\section{De natione entis et mundi. PROPOSITIO QUINTA}

Substantiae essentia est vis activa.

Probatio. Substantiae essentiam constituunt ea, per quae eius existentia sine alterius rei conceptu est intelligibilis. Atque haec illa sunt, per quae suae existentiae specimina necessario edit. Specimina autem haec nequit edere nisi agat, et omnis actio proficiscitur a vi activa, quae est eius principium. Ergo essentiam substantiae statuit vis activa, $\mathrm{q}[$ uod] et $\mathrm{d}$ [emonstrandum].

Corollarium. Omnis ergo substantia per essentiam est activa seu actuosa et in perpetua actione necessario exercetur, nullaque in mundo unquam ociatur [otiatur - nota tłumacza].

Alii metaphysici, inter quos Cantzius aliter propositionem hanc demonstrat, alia, namque substantias creatas edere debere specimina suae existentiae, ut ex iis existentia Creatoris erui possit. Creator enim eas creavit, ut ipse a nobis agnosceretur. Quam ob rem eas necessario tales effecit, ut ex iis eius existentia esset cognoscibilis: sed cognoscibilis non est nisi per specimina, ergo suae existentiae specimina necessario dant. Hanc quidem demonstrationem non damnamus, sed cum in ea usurpentur Dei fines, vim ad substantiae meram essentiam [opuszczone słowo, być może: demonstrandam habere nota tłumacza] nobis non videtur.

Ut demonstratio nostra plenum obtineat assensum exceptioni en audacter occurram. Dicet ergo quispiam: specimina existentiae substantiae dari utique debent, sed necesse non est ut dentur ab ipsa cum possint dari ab alio, v[erbi] $\mathrm{g}$ [ratia $]$ a Deo; unde non ipsa agit, non ipsa gaudet vi, sed Deus. Sed regero: si haec specimina non dentur ab ipsa substantia, sed ab alio nempe a Deo, hoc ipso non erunt vera certaque specimina existentiae substantiae, sed existentiae alterius nempe Dei ea edentis. Cum enim Deus haec edens specimina existentiae substantiae ad ea edenda non indigeat ipsa substantia, poterunt dari haec specimina, quin ipsa detur correspondens substantia. 
Re enim vera in Sacramento Eucharistiae, Deus dat specimina existentiae panis, et panis tamen in eo non existit. Inter specimina ergo a Deo data et correspondentis substantiae existentiam non datur nesessaria connexio, ita ut his positis, haec necessario existat. Unde non sunt amplius veri nominis specimina [opuszczone stowo - tłumacz] haec edere, non de aliqua solum substantiarum specie, non de creatis solum. Regero denique: Quodsi ab alio haec ederentur specimina, existentia substantiae non intelligeretur ex ipsa solum, et ad eam intelligendam rei alterius conceptu opus esset.

\section{TWIERDZENIE PIĄTE}

Istotą substancji jest siła czynna.

Dowód: istota substancji składa się z tych rzeczy, przez które można poznać jej istnienie bez wyobrażenia o innej rzeczy. Są to zatem te rzeczy, przez które dowodzi ona w sposób niezbywalny swojego istnienia. Nie można zatem stwierdzić o niej nic innego jak tylko to, że działa, każde zaś działanie wywodzi się z siły czynnej, która jest jej zasadą. Zatem to siła czynna stanowi istotę substancji, co było do okazania.

Wniosek. Każda zatem substancja z istoty swojej jest czynna czy też działająca i w sposób konieczny musi działać bez przerwy, i żadna substancja na świecie nie może pozostawać w stanie spoczynku.

Inni metafizycy, a między nimi Kantziusz, inaczej dowodzą tego twierdzenia, mianowicie że substancje stworzone muszą mieć takie cechy swojego istnienia, aby z ich można było poznać istnienie Stwórcy. Stwórca bowiem stworzył je dlatego, byśmy przez nie mogli poznać jego samego. Stworzył je takimi, jakie są w sposób konieczny, aby z nich cech można było poznać jego istnienie: a że jego można poznać tylko dzięki poznaniu tych substancji, zatem te substancje muszą być poznawalne w sposób konieczny. Nie odrzucamy wprawdzie tego dowodu, ale nie wydaje się nam, by sama siła [była dowodem] dla istoty substancji, gdyby w niej miałyby się zawierać cele Boga.

Aby można było nasz dowód w sposób pełny uznać za prawdziwy, odpowiem bez wątpliwości na twierdzenie przeciwne. Jeśliby zatem ktoś powiedział: cechy istnienia bytu dane są w sposób konieczny, ale nie jest konieczne to, by cechy pochodziły od niego samego, mogą przecież pochodzić skądinąd, np. od Boga, zatem to nie substancja jest czynna, nie ona ma siłę (czynną), ale Bóg. Ale sprzeciwiam się temu: jeśliby cechy nie pochodziły z substancji, ale skądinąd, to jest $\mathrm{z}$ Boga, to nie przynależałyby one do tej samej, tylko do 
Boga. Gdyby bowiem Bóg, dając owe cechy istnienia substancji, nie potrzebował, aby te substancje same mogły mieć te cechy, wtedy mogłoby być tak, że dane są same cechy, a nie ma substancji, która by im odpowiadała.

W rzeczy samej bowiem w Sakramencie Eucharystii Bóg daje cechy istnienia chleba, a jednak nie ma tam chleba.

$\mathrm{Z}$ tego, co przedstawiono, wynika, że pomiędzy daną od Boga cechą a odpowiadającą jej istniejącą substancją nie zachodzi związek konieczny, to znaczy taki, że substancja istnieje w sposób konieczny. Ponadto stąd cechy nie mogą w sensie dosłownym mówić tylko o jakimś pozorze substancji, nie tylko o stworzonym [?]. Odpowiadam tutaj: jeśliby owe cechy odnosiły się do czegoś innego, nie możnaby dowiedzieć się o istnieniu substancji z niej samej, i dla zdobycia wiedzy konieczne byłoby pojęcie innej rzeczy.

\section{Tłumaczyła Magdalena Lisecka}

\section{Bibliografia}

Arndt H. W., Substanz / Akzidens; Descartes bis Kant, [w:] Historisches Wörterbuch der Philosophie, hrsg. von Joachim Ritter und Karlfried Gründer, Bd. 10: St-T, Basel 1998, s. 527.

Canz I. G., Philosophia fundamentalis, Hildesheim, New York 1997.

Kant I., Principiorum primorum cognitionis metaphysicae nova dilucidatio quam consensu amplissimae facultatis philosophicae dissertatione publica in auditorio phil. die 27. Septembr. horis VIII-XII habenda pro receptione in eandem defendet $M$. Immanuel Kant, Regiom. respondente Christophoro Abrahamo Borchard, Heiligenb. Bor. S.S. theol. cultore, opponentibus Johanne Godofredo Möller, Reg. S.S. theol.stud. Friderico Henrico Samuele Lysio, Regiom. I.U.C. et Johanne Reinholdo Grube, Reg. I.U.C. anno MDCC LV Regiomonti, typis sacr. maiest. et univ. typogr. I. H. Hartungii.

Narbutas K., Raštai, Vilnius 1989 (słowo wstępne: Romanas Plečkaitis).

Narbutt O., O pierwszym polskim podęczniku logiki, Łódź 1958.

Paulsen Fr., Immanuel Kant. Sein Leben und seine Lehre, Stuttgart 1920.

Rohls J., Protestantische Theologie der Neutzeit, Bd. 1, Stuttgart 1997.

Reinbeck J. G., Canz I. G., Betrachtungen über diein der Augspurgischen Confessionenthaltene und damit verknüpfte gottliche Wahrheiten, welche Theils aus vernünftigen Gründen, allesammt aber aus heiliger göttlicher Schrift hergleitet, und zur Ubung in der wahren Gottseeligkeit angewendet werden, Gent 1745.

Rosenkranz K., Geschichte der Kant'schen Philosophie, Leipzig 1840. 
Stasiewicz-Jasiukowa I., Kaziemierz Narbutt, Warszawa-Lida 2004. Zródło net: http://pawet.net/library/history/city_district/data_people/scientists/narbutt_k/ Kazimierz_Narbutt.html [dostęp: 05.01.2015]

Wolfes M., Canz, Israel Gottlieb, [w:] Biographisch-Bibliographisches Kirchenlexikon, Bd. 18, Herzberg 2001, s. 243-258.

Tunaitis, Kantizmo sklaida, [w:] Apšvietos ir romantizmo kryžkelèse. Filosofijos kryptys ir kontroversijos XVIII a. pabaigoje - pirmoje XIX a. puseje, Vilnius 2008. Wundt M., Die deutsche Schulphilosophie im Zeitalter der Aukflärung, Tübingen 1945.

\section{Abstract \\ Since When Has Kant Been Criticized? Lithuanian Version}

This article attempts to give an arguments for the hypothesis, that Lithuanian priest of Piars Kazimierz Narbutt (1738-1807) has been the philosopher, who had an honour to be the first in East, and maybe the whole Europe, to receive and criticise the pre-critical thinking of Immanuel Kant. In 1765, in his course of philosophy at the Collegium of Piars in Dąbrowicy Narbutas criticises the concept of substance suggested by "metaphysician Cantzius". A person named as "Cantzius" could have been either Immanuel Kant, or theologian Gottlieb Israel Canz. Objecting to the position of Steponas Tunaitis, two arguments have been developed in this article: the person, who was referred to by Narbutas, couldn't have been Canz, since the latter was a representative of the theologian Wolffianism. This philosophical position is close to that of Narbutas himself, his concept of the essence of the substance is the same as that of School of Wolff. Canz couldn't have delivered the concept of substance which were opposite to that of School of Wolff. The second argument states, that the principial propositions (and their consequentials) of Kant provided in his work of 1755 Principorum primorum cognitionis metaphysicae nova dilucidatio could be attributed to the position of "metaphysician Cantzius" on the substance, its attributes and the goals of God,which had been questioned by Narbutas. This parallel provides us with an opportunity to state, that Narbutas directly or indirectly has been acquainted with the above mentioned work of Kant and that the person, referred to in the text of Narbutas, is nobody but Kant, who has been dealing with metaphysical matters at that time.

Key words: Narbutt, reception of Kant's philosophy, metaphysics, Crusius, history of 18 th century philosophy 